\title{
DERECHO ADMINISTRATIVO Y DERECHOS SOCIALES FUNDAMENTALES
}

ADMINISTRATIVE LAW AND FUNDAMENTAL SOCIAL RIGHTS

\section{Jaime Rodríguez-Arana Muñoz*}

Resumen: El presente trabajo tiene por objeto demostrar que el derecho administrativo del Estado social y democrático es el derecho del poder público para la libertad solidaria. El método empleado es el propio de la investigación jurídica, en este caso a través de la argumentación y la proyección de los principios constitucionales sobre el derecho administrativo. El estudio parte de una introducción en la que se plantea la cuestión, un análisis del llamado derecho constitucional, un comentario sobre la incidencia de la cláusula del Estado social sobre la Administración pública y el derecho administrativo que sirve de antesala para la principal conclusión: que el interés general en un Estado social y democrático de derecho está inescindiblemente vinculado a la promoción de los derechos fundamentales, individuales y sociales, de la persona. Es decir, la dignidad del ser humano es el centro y la raíz del derecho público, de manera que todas sus instituciones y categorías deben definirse y construirse desde esta perspectiva.

Palabras clave: Estado social de Derecho, dignidad humana, interés general, Administración pública, DESC

Abstract: The aim of this work is to show that the administrative law of a social and democratic state based on the rule of law is the right that the government has to liberty in solidarity. The method used is specific of legal research; in this case through argumentation and by showing the

\footnotetext{
* Catedrático-Director del Grupo de Investigación de Derecho Público Global de la Universidad de La Coruña (España). Presidente del Foro Iberoamericano de Derecho Administrativo.rajaime@gmail.com
} 
importance that the constitutional principles have on administrative law. The study opens with an introduction where the matter is put forward, followed by an analysis of constitutional law, and a comment on the incidence of the social state clause on Public Administration and administrative law that heralds the main conclusion: that general interest in a social and democratic state based on the rule of law is fully connected to the promotion of the fundamental, individual and social rights of people. In other words, that the dignity of human beings is central and at the root of public law, whereby all its institutions and categories should be defined and built from this perspective.

Keywords: Social State Based on the Rule of Law, Human Dignity, General Interest, Public Administration, ESCR

Sumario. I. Introducción. II. El derecho administrativo constitucional. III. La cláusula del Estado social. IV. Interés general y derechos fundamentales. V. Derecho administrativo y derechos sociales fundamentales. VI. Reflexión final. Referencias.

\section{INTRODUCCIÓN}

El derecho administrativo es, en el tiempo en que vivimos, una rama del derecho público que partiendo de la norma fundamental aspira a la realización efectiva del modelo del Estado social y democrático de derecho que hoy caracteriza la forma de Estado dominante en el planeta. Como es sabido, el derecho administrativo se nos presenta desde sus orígenes dependiente del interés general, de aquellos asuntos supraindividuales que a todos afectan por ser comunes a la condición humana y que reclaman una gestión y administración equitativa y que satisfaga las necesidades colectivas en un marco de humanidad, racionalidad y de justicia (Menéndez, 2016).

El derecho administrativo en sentido estricto, especialmente a partir de la Revolución francesa, surge como un derecho autoritario sobre la base del acto administrativo y sus principios atributos: ejecutividad y ejecutoriedad, propiedades inherentes a la actuación administrativa que se entienden desde ese tiempo, en buena parte hasta nuestros días, en clave de privilegio y prerrogativa (Rodríguez-Arana, 2009). La autotutela administrativa en ese momento, principios del siglo XIX, tenía sentido en el modelo de Estado que se estaba alumbrando y por ello se consideraba el derecho administrativo como un derecho esencialmente exorbitante, 
especial, que se distinguía del ordenamiento privado porque la Administración pública, su principal y único objeto de estudio, aparecía en escena acompañada de un conjunto de fenomenales potestades y poderes - entendidos, insistimos, en clave de privilegios y prerrogativas - ante los cuales sólo cabía la sumisión por parte de los administrados.

Eran tiempos en los que la legalidad administrativa procedente del Estado liberal de derecho era la guía y el norte de la actuación administrativa. $\mathrm{O}$ la Administración solo podía hacer única y exclusivamente aquello que establecía la ley — vinculación positiva- o, vinculación negativa, sólo podía hacer aquello no prohibido por la norma jurídica por excelencia. En este contexto, los derechos fundamentales de la persona eran los de libertad, los tradicionales civiles y políticos, ante los cuales el Estado no tenía más remedio que la abstención y la no interferencia.

Por cierto, los derechos civiles y políticos nacieron, es fuerza reconocerlo, anclados a una determinada manera de comprender el derecho de propiedad y, sobre todo, a una determinada clase social, la burguesía, que precisaba de instrumentos de conservación y mantenimiento del poder para afirmar su posición en la vida social, tal y como como gráficamente se deduce de la conformación sociológica de las primeras Asambleas parlamentarias de la República francesa.

El paso del tiempo contribuyó, a raíz de la industrialización y el éxodo masivo de la población del campo a la ciudad y las consiguientes limitaciones y dificultades laborales de esa etapa histórica, a que creciera la conciencia social del Estado y a que esté considerara que debía no solo defender y proteger los derechos fundamentales puramente individuales, sino que también, y de modo central, debía promover las condiciones que hicieran posible el libre y solidario desarrollo de la persona en la sociedad. Aparece el Estado social de derecho en el que la solidaridad es también una función del Estado. Más tarde, la participación social se presenta como una condición inexcusable para el diseño, implementación y evaluación de las políticas públicas y a la caracterización social del Estado se agrega su condición democrática.

En este contexto, la constitución sustituye a la legalidad administrativa como la principal fuente del derecho y comienza tímidamente un proceso en el que la Administración pública, más allá de esa legalidad administrativa, positiva o negativa, se compromete con la realización de los valores y objetivos constitucionales, especialmente de los postulados del Estado social y democrático de derecho en la cotidianeidad a través, sobre todo, de la acción del complejo gobiernoadministración pública. 


\section{EL DERECHO ADMINISTRATIVO CONSTITUCIONAL}

La primacía de los valores y principios constitucionales reclama que la legalidad administrativa se integre y se aplique a partir de estos valores, objetivos y principios. Tal tarea, lamentablemente todavía in fieri, se pone de manifiesto precisamente cuándo se estudia la funcionalidad de los derechos sociales fundamentales en el derecho administrativo, consecuencia de la proyección jurídica de la centralidad de la dignidad humana sobre el derecho público.

Es entonces cuando nos topamos con algunos valladares casi inexpugnables que impiden que, efectivamente, la luz de esos valores y principios constitucionales impregne también el quehacer de las administraciones públicas después de más de dos centurias de la célebre Revolución francesa.

En este sentido, la evolución histórica de la Administración pública y del derecho administrativo en España, a muy grandes trazos muestra también, sobre todo desde 1978, este planteamiento. Es más, el denominado derecho administrativo constitucional, del que se puede hablar con propiedad a partir de la vigente Carta Magna, exige nuevos estudios e investigaciones más conectados con los valores y principios constitucionales entre los que se encuentran, entre otros, el servicio objetivo al interés general, la centralidad de la dignidad del ser humano, la función promocional de los poderes públicos, $\mathrm{y}$, por supuesto, una concepción más abierta de los derechos fundamentales de la persona, entre los que se encuentran también los denominados derechos fundamentales sociales.

\section{LA CLÁUSULA DEL ESTADO SOCIAL}

La cláusula del Estado social ha significado una profunda transformación en el tradicional entendimiento del derecho administrativo. En efecto, el Estado debe promover las condiciones para que la libertad y la igualdad de las personas y de los grupos en que se integran sean reales y efectivas, removiendo los obstáculos que impiden su efectividad y fomentando la participación de todos los ciudadanos en la vida política, económica, social y cultural. Por tanto, esta impronta constitucional, en España reconocida en el art. 9.2 de la Carta Magna, debe presidir el sentido $\mathrm{y}$ funcionalidad de todas las categorías e instituciones del derecho administrativo. Un derecho administrativo que habrá de tener una nueva 
textura y sensibilidad, para lo que precisará de instituciones y técnicas adecuadas a las nuevas finalidades que la constitución le impone.

Especialmente relevante en la construcción del derecho administrativo constitucional es la participación ciudadana pues, como ya señaló el Tribunal Constitucional Español en una sentencia de 7 de febrero de 1984, el interés general debe definirse con participación social. Atrás quedaron las versiones cerradas y unilaterales del interés general, abriéndose las puertas a nuevas perspectivas que han de contar con la presencia y participación de los ciudadanos. Es decir, el interés general ya no se define unilateral y monopolísticamente por la Administración pública, como antaño. Ahora es preciso convocar y recibir la vitalidad real que emerge de la vida social, lo que reclama una cada vez más intensa y honda participación social.

\section{INTERÉS GENERAL Y DERECHOS FUNDAMENTALES}

En este sentido, el concepto de interés general, ahora abierto a la participación por exigencias de un Estado que se presenta como social y democrático de derecho, presenta un irreductible núcleo básico conformado precisamente por la efectividad de los derechos fundamentales de la persona, los individuales y los sociales. Es más, no se comprendería que las realizaciones y operaciones administrativas promovidas desde el interés general no estuvieran acompañadas en todo momento de su compromiso radical con la defensa, protección y promoción de los derechos fundamentales de la persona.

Los derechos fundamentales de la persona, concebidos en su origen como derechos de libertad, derechos ante los que el Estado debía declinar toda actuación, por mor de la cláusula del Estado social y democrático de derecho se amplían hacia nuevos espacios, imprescindibles para una vida digna. Es el caso de los derechos sociales fundamentales entre los que se encuentran, por ejemplo, el derecho a la alimentación, al vestido, a una vivienda digna, a la protección social, a la igualdad en el acceso al mercado de trabajo, a la educación o a la salud. En estos casos la sociedad y la institución estatal han de facilitar a las personas los medios necesarios para la satisfacción de estos derechos, concibiéndose como obligaciones de hacer en favor de ciudadanos. El derecho fundamental al mínimo vital o existencial debe estar cubierto en nuestras sociedades y, a partir de este suelo mínimo, a través de los principios de progresividad y prohibición de la regresividad de las medidas sociales, se debe caminar hacia mayores 
cotas de dignidad en el ejercicio de los derechos fundamentales de la persona.

En España, como sabemos, siguiendo la tradición alemana, no están reconocidos los derechos sociales fundamentales como derechos fundamentales de la persona, y por tanto no disponen de las consiguientes garantías de protección jurisdiccional a través del procedimiento especial sumario y preferente que diseña la Constitución. Se encuentran, y no todos, a excepción del derecho a la educación (art. 27 de la Constitución), en el marco de los principios rectores de la política social y económica del Capítulo III de la Constitución de 1978, y su efectividad depende de que se haya dictado la correspondiente norma de desarrollo y de que existan disponibilidades presupuestarias.

\section{DERECHO ADMINISTRATIVO Y DERECHOS SOCIALES FUNDAMENTALES}

Pues bien, tal situación por inaceptable - habida cuenta del tiempo transcurrido desde el que se acrisoló la formulación del Estado social y democrático de derecho- debe replantearse categóricamente. Por la sencilla razón de que si la dignidad del ser humano es el centro y la raíz del Estado y si el fundamento del orden político y la paz social, tal y como señala solemnemente el art. 10.1 de la Constitución española, residen en la dignidad de la persona, en los derechos que le son inherentes y en el libre desarrollo de la personalidad, entonces las normas, las estructuras, los procedimientos y los presupuestos deben estar al servicio del principal patrón y estándar ético y jurídico del Estado mismo al que los demás han de rendirse: la dignidad del ser humano. De ahí que la defensa, protección y promoción de los derechos fundamentales de la persona sea la principal tarea que tiene en sus manos el Estado moderno y de la que debe dar cuenta periódicamente a la ciudadanía.

Los derechos sociales fundamentales, por tanto, deben tener acomodo constitucional como derechos fundamentales que son. Y mientras ello no acontezca, siguiendo la estela del Tribunal Constitucional alemán, entre otros, nuestra más alta instancia de interpretación constitucional debería, a través de la argumentación racional, alumbrar dichos derechos como exigencias inmediatas de un Estado que se define en su constitución como social y democrático de derecho. No es de recibo que ni siquiera el derecho al mínimo vital esté reconocido entre nosotros como derecho fundamental y que no haya sido posible extraer todas las consecuencias jurídicas de los arts. 9.2 y 10.1 de la Carta Magna. Por otra parte, la 
asignación equitativa a que se refiere el art. 31.2 de la Constitución en materia de gasto pública podría abrir espacios bien pertinentes para mejorar sustancialmente la situación en que nos encontramos en esta materia.

Estos tres preceptos constitucionales (los arts. 9.2, 10.1 y 31.2) son cruciales para una construcción avanzada del Estado social y democrático de derecho entre nosotros. Son artículos de la Carta Magna que ciertamente han estado condicionados en su aplicación por prejuicios y preconceptos heredados del lastre que todavía conserva la legalidad administrativa del Estado liberal de derecho. Sin embargo, en el tiempo en que estamos, aprovechando inteligentemente la crisis general e integral que se ha desatado en estos años, deberíamos poner negro sobre blanco esta cuestión y reconocer - es el primer paso - que nuestro derecho administrativo aún sigue prisionero de determinados enfoques y aproximaciones que le impiden volar hacia su condición de ordenamiento de defensa, protección y promoción de derechos fundamentales a través de los diferentes quehaceres y políticas públicas que conforman la actuación constitucional del complejo gobierno-administración pública.

En la medida que los derechos sociales fundamentales o derechos fundamentales sociales implican ordinariamente, en virtud del superior criterio de la subsidiariedad, que es comúnmente el Estado quien debe asumir esas obligaciones de hacer que permiten el despliegue de estos derechos, el derecho fundamental a la buena administración brilla con luz propia como derecho básico para que estas prestaciones se realicen adecuadamente. Las características de la buena administración: equidad, objetividad, racionalidad y plazo razonable, aseguran que la realización de estas prestaciones públicas, en defecto de la actuación social, puedan efectivamente hacer posible en tiempo y forma el ejercicio de unos derechos que son realmente fundamentales para la existencia digna y adecuada de los ciudadanos.

En efecto, el derecho a la buena administración se enmarca en las modernas tendencias de un derecho administrativo menos apegado al privilegio y más conectado a la tarea de contribuir a la mejora de las condiciones de vida de los ciudadanos, es crucial para el normal despliegue de los derechos sociales fundamentales. Especialmente, en el caso de los derechos sociales fundamentales de mínimos, el plazo razonable en la prestación de las obligaciones que compete a la Administración, en defecto de actuación social, es de tal calibre que es determinante para que la dignidad del ser humano sea respetada o gravemente violada. Ejemplos hay y tan obvios, algunos de expresión gráfica en este tiempo, que huelgan 
demasiadas glosas o comentarios al respecto. Podemos pensar en el derecho a la educación o en el derecho a la salud, por ejemplo.

El interés general, por mucho tiempo vinculado a la protección, defensa y protección de los derechos civiles y políticos, debe abrirse ahora a la defensa, protección y promoción también de los derechos sociales fundamentales. Por una razón bien obvia, porque los derechos fundamentales de la persona, lo han confirmado y ratificado hasta la saciedad las principales cartas y declaraciones internacionales en la materia, son universales e inescindibles, porque son y pertenecen al ser humano $\mathrm{y}$, por ello, forman parte indeleble de la misma condición de miembro de la especie humana al estar inscritos en la misma dignidad que caracteriza y reconoce a las personas. La categoría de los derechos fundamentales es única y su régimen jurídico, también en lo que respecta a la protección jurisdiccional no admite despliegues o proyecciones diversas según circunstancias de oportunidad o conveniencia política.

Hoy, en un mundo en el que se aprecia una inaceptable tendencia a privatizar el interés general, el derecho administrativo debe ser un dique de contención que evite que el poder político o el poder financiero, cuándo se conciben desde la unilateralidad y desde una perspectiva hobbesiana, lamine y lesione la dignidad del ser humano, tantas veces la única y más relevante fortaleza ante las pretensiones de dominio absoluto de las terminales y tecnoestructuras del poder mismo.

Si convenimos que la dignidad del ser humano es la piedra de toque del ordenamiento del Estado social y democrático de derecho, tendremos que empezar a actualizar y replantear todas las categorías e instituciones jurídicas en esta dirección. Es una orientación — ¿quién podría imaginarlo? - que en este tiempo va contra corriente a causa de la intensa mercantilización de la vida social, política y cultural, también de la actividad pública.

\section{REFLEXIÓN FINAL}

Por eso, merece la penar recordar que la dignidad humana es de tal calibre y condición jurídica que se yergue, omnipotente y todopoderosa, frente a cualquier embate del poder político o financiero por derribarla, por lesionarla o por laminarla. Por eso, cuando por alguna causa, esa dignidad es lesionada, en el grado que sea, por acción u omisión de Entes públicos, el derecho público se nos presenta como la fuente para restaurar de inmediato la dignidad violada para que el ser humano en todo momento 
pueda estar en las mejores condiciones posibles para desarrollarse libre y solidariamente.

El derecho administrativo, como bien sabemos, ha sido a lo largo de la historia objeto de muchas definiciones y de variadas aproximaciones, tantas casi como autores han escrito sobre el particular. Desde la idea del poder, pasando por el servicio público o por la noción de equilibrio entre prerrogativa y garantía, se han sucedido muchas formas de entender esta rama tan importante del derecho público. Entre nosotros, por largo tiempo prevaleció una perspectiva subjetiva que focalizaba la cuestión en la Administración pública como punto central de nuestra disciplina. Eran los tiempos del primado del Estado liberal de derecho, los tiempos en los que la potencia de la luz revolucionaria imponía sus dictados y más o menos, con mayor o menor intensidad, se pensaba que el derecho administrativo cumplía su tarea ofreciendo una panoplia de instituciones y categorías capaces de restaurar los nocivos efectos de una Administración acostumbrada al privilegio y a la prerrogativa.

Pues bien, a pesar del tiempo transcurrido desde la formulación del Estado social y democrático de derecho no son muchos los estudiosos del derecho administrativo que han caído en la cuenta de que el derecho administrativo es algo más que un ordenamiento dispuesto para reaccionar jurídicamente contra el exceso del poder, contra la desviación del poder.

Meilán Gil (1967; 2016) es el primero que subraya la centralidad de los intereses colectivos como punctum dolens para la definición del derecho administrativo, ayudándonos a comprender el alcance — para mi casi definitivo-, del concepto de interés general en el Estado social y democrático de derecho como piedra toque del moderno derecho administrativo (cfr. Rodríguez-Arana, 2006, 2013, 2014a y 2014b).

El interés general en el Estado social y democrático de derecho, además de ser un concepto que se incardina necesariamente en la realidad cotidiana y que ha de ser expresado en forma racional, dispone de un núcleo indisponible que responde precisamente a la defensa, protección y promoción de los derechos fundamentales de la persona, los denominados de derechos libertad y por supuesto los derechos sociales. En este sentido, el derecho administrativo debe comprometerse a fondo con la cláusula del Estado social y democrático de derecho, con la promoción de las condiciones para que la libertad y la igualdad de la persona y de los grupos en que se integran sea real y efectiva, removiendo los obstáculos que impidan su cumplimiento y fomentando la participación de todos en la vida política, económica, social y cultural.

Desde este punto de vista cobra especial actualidad la tesis del profesor argentino Balbín (28-V-2014) cuándo señala que, precisamente en 
el marco del Estado social y democrático de derecho el derecho administrativo es un derecho de inclusión social (cfr. Balbín , 2004), un derecho que más allá de restaurar jurídicamente los daños causados a los ciudadanos por los poderes públicos, es un derecho preventivo precisamente comprometido con esa tarea de crear condiciones igualitarias que hagan posible el libre y solidario desarrollo de los habitantes.

En efecto, el derecho administrativo de este tiempo, más si lo contemplamos desde la estrepitosa crisis de la versión estática del Estado de Bienestar, debe replantear muchas de sus categorías y conceptos, demasiados deudores de una legalidad administrativa anclada en el siglo XIX, hoy superada por la misma definición del Estado como social y democrático de derecho. Esta investigación parte precisamente de esta consideración: la primacía de la constitución y de la forma de Estado en ella alumbrada, consideración que ha de trascender y reinterpretar el conjunto de un sistema pensado y diseñado para otro tiempo. Sencillamente, hoy la clave es la dignidad del ser humano, que es raíz y centro del Estado, y desde ahí, a partir de esta base, deberemos acercarnos a todas y cada una de las categorías que conforman el derecho administrativo. Desde las fuentes, el reglamento, el acto administrativo, los reglamentos, la actividad de limitación, de servicio público o de fomento, la potestad sancionadora, los bienes públicos y, por supuesto las diferentes expresiones sectoriales de la actividad administrativa (cfr. Arango, 2006). 


\section{REFERENCIAS}

Arango Rivadeneira, R. (2006). El concepto de los derechos sociales fundamentales. Bogotá: Universidad Nacional de Colombia.

Balbín, c. (28-V-2014). Un derecho administrativo para la inclusión social. La Ley, 1, 2.

Meilán Gil, J.L. (1967). El proceso de la definición del derecho administrativo. Madrid: Escuela Nacional de Administración pública.

Meilán Gil, J.L. (2016). Derecho Administrativo Revisado. Santiago de Compostela: Andavira.

Menéndez Sebastián, E.M. (2016). La Administración al servicio de la justicia social. Madrid: Iustel.

Rodríguez-Arana, J. (2006). El buen gobierno y la buena administración de instituciones públicas, Madrid: Aranzadi

Rodríguez-Arana, J. (2009). Derecho Administrativo Español. La Coruña: Netbiblo

Rodríguez-Arana, J. (2013). Interés general, derecho administrativo y Estado de bienestar. Madrid: Iustel.

Rodríguez-Arana, J. (2014a). Derecho Administrativo y Administración pública en tiempo de crisis, Caracas: Editorial Jurídica Venezolana.

Rodríguez-Arana, J. (2014b). Poder público y ciudadanos, Madrid: Reus.

\section{Normativa:}

España, Constitución de 1978.

España, Sentencia del Tribunal Constitucional de 7-II-1984. 